\title{
Exposições universais: Urbanização e turismo
}

\section{Universal exhibitions: Urbanization and tourism}

DOI: $10.46814 / 1 a j d v 3 n 6-026$

Recebimento dos originais: 01/11/2021

Aceitação para publicação: 15/12/2021

\author{
Marlene Matias \\ Formação acadêmica mais alta - DOUTORA EM CIÊNCIAS SOCIAIS - pela Pontificia \\ Universidade Católica de São paulo. \\ Rua Lisboa, 433 apto 72 - Cerqueira Cesar - São Paulo - SP - CEP 05413-000 \\ E-mail: marmatias@uol.com.br
}

\section{RESUMO}

O trabalho sobre as Exposições Universais: urbanização e turismo tem por objetivo identificar os tipos de intervenções urbanas que ocorrem nas cidades sedes e nas áreas destinadas a esse tipo de evento, como também buscou estabelecer as relações que ocorrem entre as Exposições Universais a urbanização e o turismo. Para a realização do mesmo utilizou-se como procedimentos metodológicos o levantamento bibliográfico para elaborar o referencial teórico, como conceitos, as origens e evolução das Exposições Nacionais Francesas, o surgimento das Exposições Universais/Mundiais, como também instrumentos legais como a Convenção de Paris 1928, os Protocolos de Modificação e as Emendas de Alteração, que estabeleceram o conceito e as diversas classificações que Exposições Universais/Internacionais receberam ao longo dos anos, após a ratificação da Convenção de Paris 1928. Após esses levantamentos e análises tornou-se possível identificar os tipos de intervenções urbanas que ocorrem nas cidades sedes e no local destinado para o evento, como também estabelecer suas relações com o turismo. O que se pode concluir é que as relações das intervenções urbanas com as Exposições Universais/Internacionais transcendem ao evento, pois ficam disponíveis para a cidade sede, população e também para o turismo.

Palavras chaves: Exposições Universais, intervenções urbanas, turismo.

\begin{abstract}
The work about Universal Expositions: urbanization and tourism aims to identify the types of urban interventions that occur in the host cities and in the areas destined to this type of event, as well as to establish the relations that occur between the Universal Expositions, urbanization and tourism. For the accomplishment of the same, it was used as methodological procedures the bibliographical survey to elaborate the theoretical referential, as concepts, the origins and evolution of the French National Exhibitions, the emergence of the Universal/World Exhibitions, as well as legal instruments such as the 1928 Paris Convention, the Modification Protocols and the Alteration Amendments, which established the concept and the various classifications that Universal/International Exhibitions received over the years, after the ratification of the 1928 Paris Convention. After these surveys and analyses it became possible to identify the types of urban interventions that occur in the host cities and in the place destined for the event, as well as to establish their relations with tourism. What can be concluded is that the relations of urban interventions with the Universal/International Expositions transcend the event, since they are available to the host city, the population and also for tourism.
\end{abstract}

Keywords: Universal Expositions, urban interventions, tourism. 


\section{INTRODUÇÃO}

O presente trabalho visa apresentar as relações existentes entre as Exposições Universais à urbanização e o turismo. Esse tema é bastante complexo devido às diversas classificações que as Exposições Universais receberam ao longo do tempo.

Para realizar as análises sobre o tema foram pesquisadas inicialmente as Exposições Nacionais Francesas, consideradas o embrião das Exposições Universais, posteriormente foram levantadas e analisadas as Exposições Universais/Mundiais que aconteceram antes da ratificação da Convenção de Paris 1928 e, registradas no Bureau International des Expositions (BIE), como tal e as Exposições Universais/Internacionais realizadas após o estabelecimento da referida Convenção.

De posse dessas informações e análises tornou-se possível identificar os tipos de intervenções urbanas que geralmente são implementados nas cidades sedes, ao serem planejadas e organizadas as Exposições Universais, como também os legados que são deixados e apropriados pelo turismo. Isso possibilitou visualizar a existência das relações das Exposições Universais/Internacionais com a urbanização e o turismo.

\section{ORIGEM E EVOLUÇÃO DAS EXPOSIÇÕES UNIVERSAIS DE 1851 A 2015}

A atividade eventos tem suas origens na Antiguidade e, em sua evolução histórica até chegar aos tempos atuais, sempre envolveu várias pessoas nas diversas fases do seu planejamento e organização, atraindo um grande número de participantes e visitantes, como também deixou valores materiais e imateriais nos locais onde aconteceram.

Ao longo da história foram surgindo vários tipos de eventos como: os Jogos Olímpicos, os Concílios, as Representações Teatrais (Católicas), os Congressos, as Feiras, as Exposições Universais e outros.

\subsection{ORIGENS DAS EXPOSIÇÕES UNIVERSAIS}

A Revolução Francesa foi o acontecimento que marcou o início da Idade Contemporânea, mas anterior a esse evento, outra revolução que já havia se iniciado e se encontrava em curso (primeira fase) na Inglaterra. Trata-se da Revolução Industrial, que também contribuiu para esse novo período da história, pois introduziu novos modos de produção.

Esses dois fatos têm em comum o nome Revolução, que é um processo que provoca uma série de mudanças políticas, econômicas e sociais, iniciando um novo período da história que se estende até o nossos dias.

Para atender aos anseios da burguesia externados na Revolução Francesa, em 1791, foi aprovada a Lei de Le Chapelier, que limitava a exclusividade da produção industrial até então 
concedida às corporações, que era um empecilho para o seu progresso. Defendia a "livre empresa" e a iniciativa privada, como também garantia a proteção de patentes, estimulando a indústria francesa. Isso instituiu o modelo econômico capitalista e a burguesia, uma nova classe econômica.

Tais medidas repressivas da Lei Le Chapelier, provocou o descontentamento da classe trabalhadora, que se rebelou, fazendo desencadear uma série de greves pedindo a extinção da Assembleia Nacional e a deposição do Rei.

Com o fim da Monarquia, na França, em 1792, é Proclamada a República, a economia do país que vinha passando por recessão devido aos conflitos anteriores, procurou buscar uma saída para a situação e, em 1797, é realizada a primeira exposição da Idade Contemporânea, por iniciativa do Marques d'Avéze, um dos poucos aristocratas que sobreviveram ao período da Revolução Francesa, que era responsável pelas Fábricas Reais, Le Gobelins. Sevres e La Savoniere. Essas indústrias fabricavam respectivamente tapetes, cerâmicas e tapeçarias, produtos que enfrentavam problemas de escoamento devido aos campos das exportações estarem fechados pelos ingleses, que bloqueavam os portos franceses numa guerra econômica, que só teve fim com a queda de Napoleão Bonaparte (1815).

A Exposição aconteceu no Castelo de Saint Cloud, um Palácio Real na França, tendo por objetivo acelerar a venda de produtos que se encontravam estocados e diminuir o desemprego das pessoas que trabalhavam nas indústrias. A maioria dos produtos que fez parte da Exposição veio das fábricas que eram administradas pelo Marques d'Avéze.

A Exposição durou apenas quatro dias, foi um sucesso comercial e também de público, demonstrando que este tipo de evento podia atrair vários outros tipos de público, além daqueles interessados em adquirir os produtos.

O sucesso da Exposição de 1797 despertou o interesse do Ministro do Interior Louis François de Neufchâteau, que juntamente com o Marques d'Avéze, planejou para o ano seguinte, a organização da primeira Exposition de Produits de l'Industrie, de caráter nacional e também a construção de instalações temporárias no Champ de Mars, para abriga-la.

A intenção da França, ao organizar a primeira Exposition de Produits de l'Industrie, além de objetivar o impulso da economia, segundo Lopes (2007: p. 19) visava também, mostrar à Inglaterra monárquica, que a liberdade da república podia promover o desenvolvimento da indústria, $e$ consequentemente, a riqueza do povo. Essa atitude da França acirrou e aumentou a concorrência política, econômica e industrial entre os dois países, pois temporariamente a França ocupou o primeiro plano no nível industrial.

Para a Exposição foi construído o Templo das Indústrias, no Champ de Mars, concebido por um dos artistas mais famosos da França revolucionária, o pintor Louis David. As instalações temporárias possuíam 60 arcos de grandes dimensões. 
A primeira edição das Exposições Nacionais Francesas, a Exposition de Produits de l'Industrie, aconteceu em 1798, foi considerada desde o início um evento festivo, aconteceu no Champ de Mars, local onde havia ocorrido todas as comemorações nacionais desde o fim da monarquia. Essa Exposição de caráter especificamente industrial, não teve nenhuma obra de arte exposta. Devido ao sucesso que alcançou a Exposição, o governo francês decidiu realizar anualmente esse tipo de evento, mas em função de inúmeras dificuldades que surgiram a $2^{\mathrm{a}}$ edição da Exposição só aconteceu em 1801, marcando o início de uma série de Exposições que aconteceram no Champ de Mars e no Louvre.

$\mathrm{Na}$ Exposição de 1802 começou a aparecer problemas de ordem de organização em relação a periodicidade e também de qualidade dos objetos expostos, devido ao curto prazo para a sua produção. A próxima Exposição só voltou a acontecer em 1806, e visando resolver os problemas de produção e qualidade dos produtos, a organização estipulou prêmios aos produtos que realmente foram aperfeiçoados e modernizados nos seus processos de produção.

As Exposições continuaram a acontecer durante o Primeiro Império Francês (1804-1814) de forma dispersa e sem expressividade, pois não existem registros sobre elas. Mas, voltaram a se reafirmar no período de 1819 a 1839, com nova periodicidade de quatro em quatro anos.

A partir de 1819, as Exposições adquiriram um caráter mais competitivo, onde o expositor buscava criar objetos originais, a fim de ganhar o reconhecimento do público e também da organização da Exposição e, se tornar merecedor da premiação, principalmente o primeiro lugar para destacar o produto e o produtor.

A Exposição de 1823 apresentou inovações nos diversos segmentos da indústria francesa, com destaque para a seda lyonnais, produto oriundo da cidade de Lyon, na França, que desde o Século XVI, por decreto do Reinado de François I (1515-1547), acolhe o Centro Têxtil francês, que funciona até os dias atuais como um verdadeiro laboratório de inovação. Além do Centro Têxtil, Lyon possui ainda o Museu dos Tecidos e das Artes Decorativas, que apresenta a história da seda.

A Exposição de 1827 foi a última a acontecer no Louvre, e como suas antecessoras apresentou inovações técnicas em relação aos processos de produção das indústrias francesas. Para a edição de 1834 foram construídos quatro pavilhões temporários na Place de La Concorde. A partir desse evento a periodicidade das exposições nacionais francesas passou a ser de cinco em cinco anos.

As edições de 1839 e 1844 aconteceram no Champs Elysées. Na Exposição de 1844 foi feita uma revisão nos princípios expositivos, isto é, foi retomada a discussão sobre a qualidade dos produtos que estavam sendo expostos e também aparece pela primeira vez a ideia de se construir espaços exclusivos e permanentes para as Exposições, ao contrário do que estava ocorrendo, a construção de pavilhões provisórios a cada quatro ou cinco anos. Porém, o crescimento do número de expositores a cada edição da Exposição, obrigou a organização a desistir dessa intenção. 
Em 1848, o Ministro do Comércio da França, Tourret, apresenta a proposta de internacionalizar a Exposition de Produits de l'Industrie, de 1849, uma vontade manifestada por Boucher e Perthes, 1834. A intenção era convidar todas as nações para participar do evento. Esse pronunciamento mexeu com as Câmaras de Comércio e Industrial francesas que, temerosas com a concorrência estrangeira protestaram e a proposta não foi aceita.

A Exposition Nationale de l'Industrie Agricole et Manufacturieri, em 1849, foi a última exposição nacional francesa, podendo ser considerada o embrião das exposições universais, pois manteve suas portas abertas nos jardins dos Champs Elysées durante seis meses, enquanto que as exposições anteriores duravam em média dois meses.

O Quadro 01, a seguir, apresenta algumas informações das Exposições Nacionais Francesas, como: locais de realização, tipo de instalações e número de expositores.

Cabe ressaltar que Paris não era única cidade francesa a realizar exposições, outras cidades como: Bordeaux, Toulouse, Lille, Dijon entre outras também possuíam Exposições, mas não tão importantes quanto as que ocorriam na capital francesa.

O interesse e admiração pela capacidade dos franceses em realizar as Exposições estimulou algumas cidades europeias - Munique, Estocolmo, Madrid, Moscou, Berlim entre outras - a enveredar na organização das suas próprias exposições, que não passaram de pálidas imitações das Exposições Nacionais Francesas.

Quadro 01 - Exposições Nacionais Francesas (1798 - 1849)

\begin{tabular}{|l|l|l|l|l|}
\hline Ano & \multicolumn{1}{|c|}{ Local } & \multicolumn{1}{c|}{ Temporário } & \multicolumn{1}{c|}{ Permanente } & \multicolumn{1}{c|}{ Expositores } \\
\hline 1798 & Champ de Mars & Sim & - & 110 \\
\hline 1801 & Champ de Mars e Louvre & $(-)$ & $(-)$ & 200 \\
\hline 1802 & $(-)$ & $(-)$ & $(-)$ & 540 \\
\hline 1806 & $(-)$ & $(-)$ & $(-)$ & 1422 \\
\hline 1819 & Louvre 1 & - & Sim & 1662 \\
\hline 1823 & Louvre & - & Sim & 1762 \\
\hline 1827 & Louvre & - & Sim & 1795 \\
\hline 1834 & Place de La Concorde & Sim & - & 2447 \\
\hline 1839 & Champs Elysées & Sim & - & 3281 \\
\hline 1844 & Champs Elysées & Sim & - & 3960 \\
\hline 1849 & Champs Elysées & Sim & - & 4532 \\
\hline
\end{tabular}

Fonte: Quadro elaborado por Marlene Matias com base em informações de diversas fontes pesquisadas.

Nota: (-) Informação não disponível.

(1) Instalação fixa, mas não específica para as Exposições.

O desenvolvimento das Exposições Nacionais Francesas era acompanhado com interesse pela Inglaterra e por outros países da Europa que passaram a visita-las.

A Inglaterra por ser o país mais desenvolvido industrialmente, e por seu papel pioneiro na Revolução Industrial sentiu-se estimulada a divulgar e internacionalizar suas ideias, produtos e 
negócios, depois que a França, a sua concorrente na disputa pela hegemonia de mercados externos, desistiu de internacionalizar a sua Exposição de 1849.

Para concretizar essa ideia, a Inglaterra contou com a sagacidade de Henry Cole, a audácia do Príncipe Albert e a confiança da Rainha Victória, que partiram para internacionalizar a realização das exposições e iniciar o ciclo das Exposições Universais com a realização da The Great Exhibition of the Works of Industry of all Nations, que aconteceu em Londres em 1851.

O surgimento das Exposições Universais causou inicialmente certa retração na organização e prática das exposições tanto nacionais quanto internacionais. Posteriormente esses eventos, estimularam os países a realizarem suas feiras e exposições como preliminares e/ou preparatórias para a participação nas Exposições Universais.

\subsection{As World Expo (Exposições Universais e/ou Exposições Mundiais) - 1851 a 2015}

A ideia de realizar uma exposição de escala mundial por parte dos ingleses foi baseada na proposta recusada pelos franceses de internacionalizar a Exposição Nacional Francesa de 1849.

Até então às exposições eram planejadas e organizadas sem nenhum tipo de regra, senão aquelas previstas pelos países onde eram realizadas, de acordo com sua organização politica, econômica e social vigente em cada época distinta.

Essa situação se evidência na Inglaterra, quando se realizou a primeira Exposição Universal e/ou Mundial a Great Exhibition of the Works of Industry of all Nations, em 1851, foi quando o Príncipe Albert, presidente da The Royal Society of Arts, entidade responsável por planejar e organizar as feiras nacionais e regionais do país percebeu que a organização e a realização de uma Exposição Universal e/ou Exposição Mundial ultrapassavam os limites e competências da instituição. Por esta razão o Príncipe Albert nomeou um Comissário Geral, que ficou responsável pela parte executiva do evento e, propôs a constituição de uma Comissão Real para organizá-la, bem como definiu critérios para a constituição da Comissão.

Os comissários da Exposição inglesa não procuraram nenhuma motivação comemorativa ou ideológica para justificar a realização do evento, mas deixaram bem claro que a principal motivação era econômica para incentivar o livre cambismo e a concorrência como mola propulsora para o progresso.

Em 1850, foi aberto um concurso para a construção do Palácio de Cristal, no Hyde Park, em Londres, para a Great Exhibition of the Works of Industry of all Nations, que é considerado o primeiro pavilhão de feiras e exposição do mundo. O concurso recebeu a inscrição de 245 projetos, mas não 
teve nenhum selecionado. Posteriormente foi solicitado ao Sir Joseph Paxton, um construtor de estufas, que apresentasse em oito dias, um projeto para um edifício de $570 \mathrm{~m}$ de comprimento.

O Palácio de Cristal foi construído com a aplicação de novas tecnologias combinando elementos como vidro, aço e concreto armado, até então não utilizados em outras construções. Apresentou uma gigantesca estrutura da qual sobressaia uma imensa abóboda de vidro, sustentada por uma armação de ferro. Essa foi a primeira utilização de vidro em grande escala, o que trouxe notoriedade para seu idealizador, Sir Joseph Paxton, além de representar um progresso considerável para a arquitetura e engenharia da civilização industrial.

Após a Exposição Universal e/ou Mundial de 1851, que aconteceu em Londres a cidade também realizou a edição de 1862, várias outras cidades sediaram o evento, são elas: Paris (1855, 1867, 1878, 1889 e 1900), Viena (1873), Filadélfia (1876), Sidney (1879), Melbourne (1880), Barcelona (1888 e 1929), Chicago (1893 e 1933), Bruxelas (1897 e 1910), Saint Louis (1904), Liége (1905), Milão (1906), Gand (1913), San Francisco (1915).

Com o aumento do sucesso das Expos, os problemas, as incertezas e as possibilidades de conflitos também aumentaram, até porque durante muito tempo as Exposições Universais e/ou Mundiais não seguiam nenhuma regra senão as previstas pelo país onde eram organizadas.

Diante dessa constatação, 1907, a França, que sempre mostrou pioneirismo na organização de feiras tanto nacionais quanto internacionais, identificou a necessidade de se estabelecer algumas regras para as Exposições Universais e/ou Mundiais. Em 1912, o governo alemão retomou o assunto realizou em Berlim a Conferência de Berlim, na qual ficou deliberado o estabelecimento das bases de um acordo internacional denominado Convenção Relativa às Exposições Internacionais, mas com o início da Primeira Guerra Mundial, o assunto foi deixado de lado. Em 1920, o governo francês inicia uma segunda tentativa para a regularização da organização e realização das Exposições Universais, que irá culminar com a Convenção de Paris de 1928, que em seu artigo 10, previa a criação de um Bureau International des Expositions (BIE), que teria por missão zelar pela aplicação da Convenção. O BIE foi criado em 1931, e tem como membros associados os países que ratificaram a Convenção de Paris 1928.

A partir da assinatura da Convenção de Paris 1928, e da criação do BIE, o planejamento e organização das exposições universais passaram a ser uma atividade instituída com base em um instrumento legal. A Convenção de Paris 1928, inicialmente buscou definir o que é uma exposição, e em seu artigo $1^{\circ}$, coloca que: 
Uma exposição é uma manifestação que, qualquer que seja a sua denominação, tem como fim principal instruir o público, ao fazer o inventário dos meios de que o homem dispõe para satisfazer às necessidades de uma civilização e fazer sobressair num ou vários ramos da atividade humana os progressos realizados ou as perspectivas do futuro.

Além de definir o que é uma exposição o BIE, passou a classificar as exposições internacionais em geral e especial, de acordo com o artigo $2^{\circ}$ da Convenção de Paris, que diz:

Uma exposição é geral quando compreende os produtos da atividade humana em vários ramos da produção ou quando é organizada com o fim de fazer sobressair o conjunto dos progressos realizados num domínio determinado, tal como a higiene, as artes aplicadas, o conforto moderno, o desenvolvimento colonial. A exposição geral pode ainda dividir-se em duas categorias que são:

- $\quad 1^{\text {a }}$ categoria - os países convidados devem construir seus pavilhões;

- $\quad 2^{a}$ categoria - os países convidados não são obrigados a construir seus pavilhões.

Uma exposição é especial quando interessa somente uma única ciência aplicada (eletricidade, ótica, química, etc.), uma única matéria prima (couros e peles, sedas, níquel, etc.), ou a uma única necessidade elementar (aquecimento, alimentação, transporte, etc.).

Ao longo dos tempos as exposições universais desde o seu surgimento até os dias atuais receberam várias classificações conforme mostra o Quadro 02 a seguir.

Quadro 02 - Denominação e Classificação das Exposições Universais/Internacionais - 1851 a 2016

\begin{tabular}{|l|ll|}
\hline Período & \multicolumn{2}{|l|}{ Denominação das Exposições Universais e/ou Internacionais } \\
\hline 1851 a 1935 & $\bullet$ & Exposição Universal (França). \\
& $\bullet$ & Exposição Mundial (Inglaterra). \\
\hline 1935 a 1983 & $\bullet$ & Exposição Geral: \\
& & $0 \quad 1^{a}$ categoria; \\
& & \\
& & $2^{a}$ categoria. \\
& $\bullet$ & Exposição Especial. \\
\hline 1983 a 1995 & $\bullet$ & Exposição Universal; \\
& $\bullet$ & Exposição Especializada. \\
\hline 1995 a 2016 & $\bullet$ & World Expo - Exposição Registrada. \\
& $\bullet$ & International Expo (Especializada) - Exposição Reconhecida. \\
\hline
\end{tabular}

Fonte: Elaborado por Marlene Matias, 2016, com base nos Protocolos de Modificação e Emenda de Alteração da Convenção de Paris 1928.

O Quadro 03 a seguir apresenta as Exposições Universais realizadas no período de 1851 a 2015, cabe ressaltar que são citadas todas as exposições que receberam a denominação de universal e/ou mundial antes da Convenção de Paris 1928 e, as exposições que passaram a ser denominadas como tal, após a ratificação da referida Convenção, conforme citado no Quadro 02, acima.

Como se pode observar ainda no Quadro 03, após a institucionalização e a criação de regras para o planejamento e organização das Exposições Universais, houve uma diminuição no número de exposições realizadas. 
Quadro 03 - As Exposições Mundiais de 1851 a 2015

\begin{tabular}{|c|c|c|c|}
\hline ANO & EXPOSIÇÃO UNIVERSAL & TEMA & LOCALIDADE \\
\hline 1851 & The Great Exhibition of the Works of Industry of all Nations & Indústria de todas as Nações & Londres/Inglaterra \\
\hline 1855 & $\begin{array}{l}\text { Exposition Universelle des Produits de l'Agriculture, de } \\
\text { l'Industrie et des Beawx Arts de Paris } 1855\end{array}$ & Agricultura, Indústria e Belas Artes. & Paris/França \\
\hline 1862 & London International Exhibition an Industry and Art 1862 & Indústria e Artes & Londres/Inglaterra \\
\hline 1867 & Exposition Universelle de Paris 1867 & Agricultura. Artes e Indústria & Paris/França \\
\hline 1873 & Well Austellung 1873 in Wien & Cultura e Educação & Viena/Austria \\
\hline 1876 & $\begin{array}{l}\text { Centenal Exhibition of Arts, Manufactures and Products of the } \\
\text { Soil and Mine }\end{array}$ & $\begin{array}{l}\text { Celebração do Centenário da Independência Americana e da } \\
\text { Declaração de } 4 \text { de julho de } 1776 \text {. }\end{array}$ & $\begin{array}{l}\text { Filadélfia/Estados } \\
\text { Unidos }\end{array}$ \\
\hline 1878 & Exposition Universelle de Paris 1878 & Agricultura, Belas Artes e Indústria. & Paris/França \\
\hline 1880 & $\begin{array}{l}\text { International Exhibition of Arts, Manufactures and Agricultural } \\
\text { and Industrial Products of all Nations }\end{array}$ & $\begin{array}{l}\text { Artes, fabricações, agricultura e produtos industriais de todas } \\
\text { as nações. }\end{array}$ & Melbourne/ Austrália \\
\hline 1888 & Exposicion Universal de Barcelona 1888 & Barcelona & Barcelona/ Espanha \\
\hline 1889 & Exposition Universelle de Paris 1889 & Comemoração da Tomada da Bastilha & Paris/França \\
\hline 1893 & $\begin{array}{l}\text { Quatriéme Centenaire de la Découverte de l'Amerique (célébré } \\
\text { avec un an de retard) }\end{array}$ & $\begin{array}{l}4^{\circ} \text { Centenário da Descoberta do novo Mundo por Cristóvão } \\
\text { Colombo }\end{array}$ & $\begin{array}{l}\text { Chicago/Estados } \\
\text { Unidos }\end{array}$ \\
\hline 1897 & Exposition Internationale de Brwxelles & O orgulho e o preconceito da Era Colonial & Bruxelas/Bélgica \\
\hline 1900 & Exposition Universelle et Internationale de Paris 1900 & O balanço do século & Paris/França \\
\hline 1904 & Louisiana Purchase/Saint Louis 1904 & $\begin{array}{l}\text { Celebração do Centenário da Aquisição do Território de } \\
\text { Louisiana em } 30 \text { de abril de } 1803\end{array}$ & $\begin{array}{l}\text { Saint Louis/ Estados } \\
\text { Unidos }\end{array}$ \\
\hline 1905 & Exposition Universelle de Liège, 1905 & $\begin{array}{l}\text { Comemoração do } 75^{\circ} \text { Aniversário da Independência da } \\
\text { Bélgica }\end{array}$ & Liège/Bélgica \\
\hline 1906 & Esposizione Internazionale del Sempione, 1906 - Milan 1906 & Transporte & Milão/Itália \\
\hline 1910 & Exposicion Universelle et Internationale de Brwxelles, 1910 & Bruxelas & Bruxelas/Bélgica \\
\hline 1911 & Turin 1911: The World's Fairs in Italy & O trabalho e a indústria & Torino/Italia \\
\hline 1913 & Exposition Universelle et Internationale de Gand 1913 & Exposition Universelle et Internationale de Gand 1913 & Gand/Belgica \\
\hline 1915 & Panama Pacific International Exposition, San Francisco 1915 & $\begin{array}{l}\text { Inauguração do Canal de Panamá e Celebração do Centenário } \\
\text { da construção de São Francisco }\end{array}$ & $\begin{array}{l}\text { São Francisco/ } \\
\text { Estados Unidos }\end{array}$ \\
\hline
\end{tabular}


Continuação:

\begin{tabular}{|l|l|l|l|}
\hline 1929 & Exposicion Internacional de Barcelona & Exposicion Internacional de Barcelona & Barcelona/Espanha \\
\hline 1933 & A Century of Progress, International Exposition, 1933-34 & Um século de progresso & Chicago/Estados \\
Unidos & Bruxelas/Bélgica \\
\hline 1935 & Exposition Universelle et Internationale de Bruxelles, 1935 & Transportes e colonização & Bruxelas/Bélgica \\
\hline 1958 & Exposition Universelle et Internationale de Bruxelles 1958 & Por um mundo mais humano & Osaka/Japão \\
\hline 1970 & Nipon Bankoku Hakurankai - Exposition Universelle du Japon & O progresso e a harmonia da humanidade & Sevilha/Espanha \\
\hline 1992 & Exposicion Universal de Sevilla 1992 & A Era dos Descobrimentos & Hannover/Alemanha \\
\hline 2000 & Exposition Universelle Hanovre 2000 - Hannover 2000 & O homem, a natureza e tecnologia & Aichi/Japão \\
\hline 2005 & Exposition Universelle Aichi 2005 & Sabedoria da Natureza & Shangai/China \\
\hline 2010 & World Exposition Shangai 2010 & Cidade melhor, vida melhor & Milão/Itália. \\
\hline 2015 & Esposizione Universale Milano 2015 & Nutrir o planeta, energia para a vida & \\
\hline
\end{tabular}

Fonte: Elaborado por Marlene Matias com base nas informações do site do BIE: http://www.bie-paris.org/site/en/expos/introduction-to-expos/world-expos. Acesso em 11/01/2014 e no Guia da Expo Milão 2015.

Nota: (-) Informação não disponível. 


\section{AS EXPOSIÇÕES UNIVERSAIS: URBANIZAÇÃO E TURISMO}

A urbanização e o turismo sempre estiveram presentes na organização e realização das Exposições Universais. Essa presença pode ser observada anteriormente em menor escala nas Exposições Nacionais Francesas, porque elas demandavam áreas físicas menores para a construção de seus pavilhões temporários, como também utilizavam instalações já existentes, portanto, precisando de intervenções urbanas pontuais. Com a abrangência apenas nacional, devido às barreiras comerciais existentes no país, limitou-se somente à visitação de turistas nacionais, que segundo Beni (2004: p.440), são pessoas residente no país, que se desloca a um lugar dentro do próprio país, distante de sua residência permanente, por mais de 24 horas, realizando pelo menos um pernoite.

Nas Exposições Universais a urbanização na cidade sede aparece de forma marcante na fase do pré-evento, que é quando a cidade e o local destinado à exposição são preparados para receber o evento. Essa preparação engloba uma série de intervenções urbanas que geralmente são implementadas, tais como:

- Recuperação de áreas ou até mesmo de bairros inteiros degradados;

- Construção de instalações para abrigar o evento, que depois ficam para uso da cidade sede;

- Melhoria dos meios de transportes urbanos, principalmente os que dão acesso ao local do evento;

- Construção de anéis viários para melhorar o fluxo do trânsito;

- Recuperação e ampliação da malha viária;

- Implementação de equipamentos de lazer e entretenimento;

- Construção, recuperação e ampliação de estações ferroviárias e rodoviárias, aeroportos e portos;

- Implementação de serviços diversos;

- Paisagismo; e

- Outros.

$\mathrm{Na}$ área destinada ao evento são construídos pavilhões permanentes e temporários (que são demolidos após o evento ou transferidos para outros locais), obras arquitetônicas e também outros tipos de edificações necessários a realização do evento.

O turismo sempre marcou presença nas Exposições Universais, desde sua primeira edição em 1851, em Londres, que aconteceu no Palácio de Cristal. Segundo registros da época o evento recebeu 6.039.105 visitantes, sendo que desse total, 165 mil foram por meio de viagem organizada pelo inglês Thomas Cook. A construção do Palácio de Cristal e a visão empreendedora de Thomas Cook formaram o casamento ideal para sedimentar o desenvolvimento do Turismo de eventos, que é: 
o conjunto de atividades exercidas por pessoas que viajam a fim de participar dos diversos tipos de eventos que visam ao estudo de alternativas, de dimensionamento ou de interesse de determinada categoria profissional, associação, clube, crença religiosa, corrente científica ou outra organização com objetivos nos campos científicos, técnicos e religiosos para atingir metas profissionais e culturais, técnicos e operacionais, de aperfeiçoamento setorial ou de atualização. (ANDRADE: 1992 apud MATIAS: 2010: p.54).

Conforme o exposto pode-se constatar que a urbanização e o turismo transcendem a realização das Exposições Universais, porque tanto as intervenções urbanas, quanto as obras arquitetônicas que são deixadas como legado para a cidade sede e para a população, que ficaram disponíveis para serem usufruídas e atender às necessidades dos visitantes/turistas.

Por ocasião da realização das Exposições Universais as cidades sedes têm áreas degradadas que são recuperadas e urbanizadas, serviços de infraestrutura básica e de transportes que são ampliados e/ou construídos, equipamentos de lazer e entretenimento e monumentos são construídos.

Os locais urbanizados e monumentos que foram construídos por ocasião das Exposições Universais, que foram apropriados pelo turismo, destacam-se: Park Prater (Viena 1873), Par de la Ciudadella (Barcelona 1888), Torre Eiffel (Paris 1889) Parque Montijuich (Barcelona 1929), Atomium (Bruxelas 1958) e Isla de la Cartuja (Sevilha 1992). Atualmente os locais que foram urbanizados e os monumentos construídos para as Exposições Universais são usufruídos pelo turismo como atrativo turístico histórico-cultural, do subtipo monumentos que segundo Beni (2007: p. 307), são:

[...] todas as obras - bens imóveis e móveis - produzidos pelo homem (da préhistória a época atual) considerados testemunho cultural e apresentadas, de modo genérico, como obras arquitetônicas de escultura e pintura e outros legados de valor científico, histórico e estético, desde que permitam a visitação pública e/ou sejam elementos componentes da paisagem.

Essa apropriação dos atrativos turísticos histórico-cultural, do subtipo monumentos é estimulada pela prática cultural, que desencadeia o desenvolvimento do turismo. Bourdieu e Darbel (2003: p. 69) colocam que:

[...] a aspiração à prática cultural varia como a prática cultural e que a "necessidade cultural" reduplica à medida que esta é satisfeita, a falta de prática é acompanhada pela ausência do sentimento dessa privação; considerando também que, nesta matéria, a concretização da intenção depende de sua existência, temos o direito de concluir que ela só existe se vier concretizar. O que é raro não são os objetos, mas a propensão em consumi-los, ou seja, a "necessidade cultural" que, diferentemente das "necessidades básicas", é produto da educação: daí, segue-se que as desigualdades diante da Escola que cria a "necessidade cultural" e, ao mesmo tempo, oferece os meios para satisfazê-la. [...] A obra de arte considerada enquanto bem simbólico não existe como tal a não ser para quem detenha os meios de apropriarse dela, ou seja, decifrá-la. [...] todas as condutas dos visitantes e todas as suas atitudes em relação às obras expostas estão associadas, direta e quase 
exclusivamente, à instrução avaliada, seja pelos diplomas obtidos, seja pela duração da escolaridade.

Para Leite (2004: p. 35), os lugares (atrativos turísticos, do subtipo monumentos) e os espaços públicos, deixados pelas Exposições Universais, na experiência urbana contemporânea significam:

\begin{abstract}
A noção de lugar, menos genérica e abrangente que a de espaço, retém uma distinção: podemos entender os lugares como demarcações físicas e simbólicas no espaço, cujos usos os qualificam e lhes atribuem sentidos de pertencimento, orientando ações sociais e sendo por estas delimitados reflexivamente. Um lugar pode, enfim, ser entendido como uma forma estriada de espaço. [...] No espaço estriado as linhas, os trajetos, tem tendência a ficar subordinados aos pontos: vai-se de um ponto ao outro. (DELEUZE e GUATTARI, 2005: P. 147, apud LEITE, 2005: P.35)
\end{abstract}

As Exposições Universais deixam lugares como demarcações físicas e simbólicas nos espaços onde ocorrem transformando-os em espaço estriado, porque estes lugares serão considerados pontos que irão originar as linhas, os trajetos, que vão de um ponto a outro, que será percorrido pelos visitantes e/ou turistas.

\title{
4 CONSIDERAÇÕES FINAIS
}

O presente trabalho buscou identificar a presença da urbanização e do turismo, na realização das Exposições Universais. Inicialmente foram apresentadas algumas considerações sobre as Exposições Nacionais Francesas que já mostravam a prática da urbanização e do turismo em menor escala.

Por fim adotou-se referencial teórico que possibilitou uma reflexão que mostra que tanto as intervenções urbanas quanto as ações de turismo identificadas, transcendem ao evento, ficando disponíveis para a cidade, a população e aos visitantes/turistas estimulando a prática cultural, isto é, a sua apropriação pelo turismo como atrativo turístico do tipo histórico-cultural. 


\section{REFERÊNCIAS}

Beni, M. C. (2004). Análise Estrutural do Turismo (10ª ed.).São Paulo: Editora Senac São Paulo.

Bourdieu, P. e Darbel, A. (2003). O amor pela arte: Os museus de arte na Europa e seu público. Porto Alegre: Zouk.

Brasil. Ministério da Indústria e Comercio (sd.). Feiras e Exposições. Brasília.

Bureau International des Expositions (1932). Convenção de Paris 1928. Paris.

Consiglio di Admministrazione (2015). Expo Milano 2015 - Guide Breve. Milão.

Koch, W. (1982). Estilos de Arquitetura II. Lisboa: Presença.

Levy, R. (2008). Entre Palácios e Pavilhões: A Arquitetura Efêmera da Exposição Nacional de 1908. Rio de Janeiro: EBA/UFRJ.

Leite, R. P. (2004). Contra-usos de cidade: lugares e Espaço Público na Experiência Urbana Contemporânea. Campinas/SP: Editora Unicamp.

Limena, M. M. (2001). Cidades Complexas no século XXI: ciência, técnica e arte. Tese de doutorado. PEPG de Ciências Sociais da Pontifícia Universidade Católica de São Paulo.

Lopes, A. P. Q. (2007). Exposições Universais Parisienses Oitocentistas. Trabalho apresentado para exame de licenciatura em Arquitetura, na Faculdade de Ciências e Tecnologia de Coimbra. Coimbra.

Marçola, E. Antecedentes à Torre: Exposições Universais do Século XIX. Disponível em: http://omundopreepostorreeiffel.blogspot.com/2008/11/antecedentes-da-torre-exposies.html. Acesso em 18/04/2012.

Matias, M. Organização de Eventos: procedimentos e técnicas (5 $5^{\mathrm{a}}$ ed.). Barueri/SP.: Manole.

Sites:

http://www.bie-paris.org. Acesso em 31/10/2010.

http://www.fact-index.com/i/li/list_of_world_s_fairs.html. Acesso em 01/11/2010.

http://www.spartacus.schoolnet.co.uk/Jarts.html. Acesso em 30/10/2010. 